\title{
Family Interactions Among African American Prostate Cancer Survivors
}

\author{
Randy A. Jones, PhD, RN, Ann Gill Taylor, EdD, RN, FAAN, Cheryl Bourguignon, PhD, RN, \\ Richard Steeves, PhD, FNP, FAAN, Gertrude Fraser, PhD, Marguerite Lippert, MD, Dan \\ Theodorescu, MD, PhD, Holly Mathews, PhD, and Kerry Laing Kilbridge, MD, MSc \\ From the School of Nursing (Drs Jones, Taylor, Bourguignon, and Steeves), the Center for the Study \\ of Complementary and Alternative Therapies (Drs Taylor and Bourguignon), and the Department \\ of Urology (Drs Lippert and Theodorescu), University of Virginia, Charlottesville (Dr Fraser); the \\ Department of Anthropology, East Carolina University, Greenville, NC (Dr Mathews); and the \\ Massachusetts General Hospital, Boston (Dr Kilbridge).
}

\begin{abstract}
Prostate cancer affects African Americans at a higher rate than any other ethnic group in the United States. Prostate cancer does not only affect the man with the disease but also affects those individuals who are closest to him, such as his family and friends. Open communication is valuable in coping with stressors that are affiliated with chronic illnesses. This article focuses on family and friend social support of men with prostate cancer. Data analysis revealed that support from family members and friends plays an important role in how men cope with their treatment and recovery from prostate cancer.
\end{abstract}

\section{Keywords}

African American men; family support; prostate cancer; survivorship

Prostate Cancer is the most commonly diagnosed cancer in men and is the second leading cause of cancer deaths among men in the United States, following lung cancer. The American Cancer Society ${ }^{1}$ estimated that in 2007 , there would be approximately 219,000 newly diagnosed cases of prostate cancer and nearly 28,000 men would die from prostate cancer.

Prostate cancer disproportionately affects African American (AA) men. They have the highest incidence of prostate cancer, at 255.5 cases per 100,000 in comparison with 161.4 cases per 100,000 Caucasian men and 140.8 cases per 100,000 Hispanic men. ${ }^{2}$ The incidence rate peaked in AA men in 1993 and has been declining, but the reasons for the higher incidence rate among AA men in comparison with Caucasian and Hispanic males is unclear. According to the latest American Cancer Society statistics, approximately 31,000 AA men would be diagnosed with prostate cancer in 2007 and an estimated 4,240 AA men would die from prostate cancer in 2007.3 The 5-year prostate cancer relative survival rate for men of all races and all age groups was $98.9 \%$ from 1996 to 2004.2 The 5-year overall survival rate of prostate cancer for AA men diagnosed with prostate cancer was $95.4 \%$ in comparison with $99.5 \%$ in White men from 1996 to 2004.2

Copyright (C) 2008 Wolters Kluwer Health | Lippincott Williams \& Wilkins

Corresponding author: Randy A. Jones, PhD, RN, School of Nursing, University of Virginia, PO Box 800782, Charlottesville, VA 22908 (raj9c@virginia.edu). 
Prostate cancer affects not only the man with the disease but also his entire family. Family relationships play an important part in how men with prostate cancer cope with the disease and decide on treatment issues. Mellon and Northouse ${ }^{4}$ found a $63 \%$ decline in overall family quality of life after a family member had been given a cancer diagnosis. Cancer diagnosis and treatment-related issues such as fatigue, pain, hopelessness, financial concerns, and grief affect the family unit. Several studies ${ }^{5,6}$ have reported correlations between the psychosocial adjustment of patients with cancer and that of their spouse or close family member. Boehmer and Clark $^{7}$ found among married men with metastatic prostate cancer that although the wives of these men were very concerned about their husbands' disease, there was little communication about the cancer, treatment options, and the emotions associated with having a diagnosis of cancer. This lack of communication may weaken coping mechanisms and decrease the resources available to men. Enhanced support, communication, and guidance from family and friends about difficult issues, such as sexual activity and fatigue, may play an important part in the lives of AA men with prostate cancer.

Family support and function have been found to be critical in how the patient and his family members are affected by chronic disease. Kiley et al ${ }^{8}$ found that among individuals who had kidney transplants, those individuals who had reduced family support had a higher risk for nonadherence to therapy, which might lead to a poorer prognosis than those with family support. Meyerowitz and colleagues ${ }^{9}$ found that perceived social support from family members was associated with emotional resilience and vitality in women with cervical cancer. In addition, Ashing-Giwa and colleagues ${ }^{10}$ found that AA, Latina, and Asian American women relied on their family and faith in God in promoting healing and recovery from disease. Another study ${ }^{11}$ that focused on couples' experiences after prostatectomy found that men viewed their wives as an important source of support for managing anxiety through the wives' reassuring that they understood and accepted the potential adverse effects of treatment, such as incontinence and impotence. It has been noted that wives of men with prostate cancer do not view intercourse as being the only route to intimacy; they can be satisfied with other ways of expressing loving feelings. ${ }^{12}$ In addition, a study ${ }^{13}$ that focused on men with prostate cancer and their partners' experiences reported that most men's female partners did not identify the absence of intercourse in the relationship as a problem.

Social support has the potential to improve coping and enhance health, particularly among individuals with chronic illnesses. It can help protect individuals from potential harm and facilitate coping with cancer. Studies ${ }^{14-16}$ have demonstrated an association between social support and improved quality of life in patients with cancer. For instance, a study ${ }^{17}$ that focused on breast cancer in women found that social support was helpful in decreasing moments of anger and depression.

Langford and colleagues ${ }^{18}$ described social support as having 4 components: emotional, instrumental, informational, and appraisal support. Emotional support includes respecting, loving, and helping to enhance psychologic well-being and a sense of optimism for an improved quality of life. Instrumental support is the provision of tangible goods and services that concretely assist individuals, such as offering financial assistance for payment of hospital bills. Informational support may include assisting individuals with solving problems during a time of stress by providing information, such as a healthcare provider talking with a patient with prostate cancer about treatments for impotence. Appraisal support involves affirming the appropriateness of an individual's decisions by providing feedback or comparing one's thoughts and feelings to those of others in similar situations. This is done through conversations with a healthcare provider, a family member, and/or a friend. Family and friends offering these types of support may help men cope effectively with the daily challenges of having prostate cancer. 
Few studies have examined the effect that family and friends can have specifically on men with prostate cancer, and even fewer have examined the important influential relationships of family and friends' networks on AA men with prostate cancer. Family and friends' networks have been shown to be important sources of social support for AAs; therefore, these relationships need to be studied in prostate cancer. ${ }^{19,20}$ Family-centered healthcare is central to improving the quality of support provided to men with prostate cancer, both within the health system and within the men's social networks. Thus, this article examines the importance of family and friends' involvement with men during treatment and recovery from prostate cancer.

\section{METHODS}

As part of a larger ongoing study ${ }^{21}$ focused on the development of culturally competent assessment instruments and prostate-specific health status terms for AA men of lower socioeconomic status, our study examined the interactions and impact of family and friends of prostate cancer survivors.

\section{Sample, setting, and procedure}

A total of 14 participants were interviewed in this study. Five participants were recruited from the prostate cancer center at a large southeastern medical center, and 9 were referred by other participants. Participants met the following criteria: (1) 18 years or older; (2) AA race, (3) diagnosis of prostate cancer and had completed cancer treatment, (4) willingness to talk about attitudes and beliefs regarding complementary practices and products as well as allopathic medicine, and (5) ability to provide informed consent.

Data collection was conducted in one of several clinic meeting rooms, the participant's home, or other nonintimidating setting for the convenience of the study participant. Individuals generally talk more comfortably about their health beliefs, attitudes, and practices when they are in a setting in which they do not feel threatened. ${ }^{22}$ In addition to having a nonthreatening environment in which to conduct the interviews, the principal investigator is an AA man sensitive to and knowledgeable about the interviewees' cultural background.

A semistructured interview guide was used to help lead an interview of approximately 1 to 1.5 hours. Each participant was asked about interactions with family members or friends because they related to his prostate cancer. The social interaction questions generated conversation that led to participants' more active responses and richer information about the men's perceptions of relationships with family and friends.

\section{RESULTS}

The 14 participants aged between 51 and 83 years, with a mean of 69.6 years. Most participants had completed 12 years of formal education, were married, and had an annual household income of less than $\$ 40,000$. All of the participants had medical insurance (ie, Medicare, Medicaid, and/or private). Approximately $57 \%$ of the participants had a family history of prostate cancer and half $(n=7)$ had undergone a prostatectomy. Demographic details are shown in Table 1.

Participants' responses throughout the interview were audiotaped and actions observed and recorded in field notes by the interviewer. The interview tapes were transcribed and analyzed using a qualitative method. The transcripts were coded, and segments of feedback (strips) collected, organized, and placed in categories, thus permitting description of commonalities within the strips. Themes were then generated from the following categories: (1) spiritual needs are important to health, (2) the value of education, (3) trust in healthcare providers is necessary, and (4) how men decide on what to believe. These themes have been discussed elsewhere (see 
Jones et al23). Members of the research team reexamined the interview data for the purposes of this article, and 2 themes emerged: (1) the importance of family involvement with prostate cancer treatment decision making and (2) the effect of prostate cancer on relationships with women.

\section{Family involvement with prostate cancer treatment decisions}

Throughout the interviews, a prominent theme was family involvement with prostate cancer treatment. Participants revealed that their family members played a major role in making a decision about the type of treatment that the men received. The women in the participants' lives, particularly the wives, were significantly involved in assisting the men with treatment decisions. When the treatment options were discussed with the physician, each of the men valued his wife's or family member's opinion on which treatment option would be best for him. One participant stated "Well, it was just a family thing. I talked it over with her, and I kept listening to the doctors, and we had a talk before I went with the operation. She attended all of the appointments." In addition, another man noted that his sister and his family overall were important assets when deciding which treatment he should receive. He said:

After talking with the doctor for a while.... I went to him about 3 times before I made a decision about which route I wanted to go. I decided that radical prostatectomy was the best way to go ... my sister was a great influence, my family was a great influence in making the decision of having the surgery over the [radiation seed] implants.

\section{Effect of prostate cancer on relationships with women}

Although the participants considered prostate cancer a significant diagnosis, most men did not view their disease or the treatment as a problem in their relationships with women. When asked how prostate cancer and its treatment affected the man and his wife or female friend, responses included: "So far it has not bothered nothing." "It doesn't bother [us]. We're up in age ... so we are most contented now." "Not really, she don't complain about it... Ain't no problem as far as I know."

Most men $(78.6 \%, n=11)$ did not believe that a woman would leave a man who had a prostate cancer treatment that led to impotence. Approximately $86 \%(n=12)$ of the sample thought that men who had had surgery for prostate cancer treatment continued to be attractive to women. In addition, the entire sample believed that women would most likely stay with them even after learning that the men had prostate cancer. These men had a high regard and belief that the women in their lives were loyal and would stand beside them while they were seriously ill, more than their male friends or relatives would. They perceived the women in their lives to be understanding of any treatment and disease adverse effects, particularly impotence. However, as shown in the following interview excerpt, it was not always clear that these adverse effects were discussed explicitly:

See with my age, I don't worry about it [sex] too much. You know, my lady friend, one thing about her is that she don't bother me too tough [much] no way. She ain't bothering nothing and I ain't bothering nothing [sex].... I ain't lying ... she don't say anything and I'm not going to say anything.

In this case, the man has positive perceptions about his relationship with his partner, but there did not appear to be discussion of the sexual adverse effects between them. The man's perception that everything is okay in the relationship may be skewed by wishful thinking because he and his partner are not speaking openly about how his treatment has affected both of them.

Some men felt that the women in their lives were more knowledgeable about prostate cancer and health in general than the men. One participant stated: 
By speaking to groups and church groups and other functions on prostate cancer and the experience and what happened to me, I think women are more up to par on health issues than men, and I think they [men] need to be aware. I think they [women] encourage their partners to have better checkups and to find if there is something wrong. I know after speaking to a number of groups, I found that many men have been diagnosed with prostate cancer because of the women....

Many of the participants, especially the 9 married men, noted the impact that their family members had on the decisions they made during their experiences with prostate cancer. As these men were being interviewed, it appeared that they had not really understood or thought about the role that their wives played during this health crisis until they were asked specifically about it during these interviews. Other studies ${ }^{24,25}$ suggest the important role spouses play in gathering information and advising about treatment. The participants also perceived physicians playing an important role through discussion of treatment options and medical information that assisted the men and their family members or peer supporters in making a decision about their prostate cancer therapy.

\section{Discussion of participants' responses}

The influence of family involvement with prostate cancer treatment was very important for this group of 14 men. Overall, the participants saw the interactions between themselves and the family members as positive. Although the men considered their physicians' advice, they also took the advice of their family members seriously, particularly the advice from their wives. Most $(n=9)$ of these men were married and had a support system that helped them with decisions during the period they were undergoing treatment for their prostate cancer. However, those men who were single $(n=2)$ or widowed $(n=3)$ relied on a family member (eg, sister), friend, or the physician alone to help make decisions.

The theme effect of prostate cancer on relationships with women is also important. Most men did not think that their male role in a relationship with the women in their lives changed significantly, even when adverse effects (eg, incontinence and impotence) were issues. Their experiences reflected that the women in their lives would not leave them or think of them negatively because they had been treated for prostate cancer. There appears to be some disconnect in communication between the man with prostate cancer and his partner about how treatments have affected them both; however, the women in the men's lives, particularly their wives, were very supportive and tried to help in any way possible. One man stated "She [wife] knew all about it [prostate cancer]. She was with me when the doctor explained everything to me, and she understood. She stood by me $100 \%$." The men appeared to describe what they interpreted to be their partners' concern about all aspects of their health rather than whether the men would be able to have sexual intercourse again. The majority of the men felt that their sex life was important and their main complaint was the quality of their erections, but at the same time, sex did not take precedence over being alive. The relative comfort that these men felt about their sex lives may have been because of their perception that the women in their intimate relationships did not consider sexual intercourse a priority in their lives in comparison with the overall health of the man and his presence in the relationship.

\section{CONCLUSION AND IMPLICATIONS}

The men in this study recognized the significance of family and friend support during this chronic illness. It is important to understand that prostate cancer has an effect beyond the patient, as it involves other people in his environment, especially family members. Men tend to be reluctant to seek healthcare and less likely to talk about their problems with their peers or healthcare providers until a disease has progressed. ${ }^{26}$ This study describes the importance 
of understanding that managing prostate cancer is a collaborative team effort, especially for AA men, who may not readily speak openly about their health issues.

More research is needed to determine whether these participants' views and experiences are representative of the larger population; however, the findings from this study have relevance and importance to healthcare professionals who care for individuals with prostate cancer.

Healthcare providers and family members, particularly a spouse, partner, or chosen friend, are important participants in the education and decision-making process faced by those with prostate cancer. Open communication among family members may improve the support system during prostate cancer therapy and recovery. Culture plays an important part in the experience of an illness such as prostate cancer and the behavior of individuals seeking healthcare. This study's findings may help healthcare providers to tailor prostate cancer healthcare plans for specific populations.

The men in this study valued the interviews as an opportunity to speak openly about the effects of prostate cancer and to think about the support they had received during their treatment and recovery. Further studies are needed to focus on interventions that quantify and qualify the influence of family and friend involvement with the care of men, particularly AAs, with prostate cancer. This study has led to other interesting questions that one might explore, including the following: Who supports the wives/families of men undergoing prostate cancer therapy? What do the wives think about their husbands' non-communication with them about intimacy issues? How do they cope? Do the relatively young couples really think that they will no longer "have sex" if the man is impotent? What sex education is available for these couples, or for the women? How can the members of the healthcare team, particularly nurses working in the field, support the importance of the partner or spouse's role for men undergoing prostate cancer therapy? How effective are prostate cancer support groups? What additional support can the healthcare system offer these families in terms of the 4 components of social support? Answers to questions such as these will open communication between men with prostate cancer and their partners as they join together to make decisions and cope with prostate cancer, treatment, and the aftereffects.

\section{Acknowledgments}

This research was supported by grants T32-AT-000052, from the National Center for Complementary and Alternative Medicine (NCCAM) to the University of Virginia Center for the Study of Complementary and Alternative Therapies, and K07-CA-085754, from the National Cancer Institute (NCI) to the University of Virginia Department of Public Health Sciences. Its contents are solely the responsibility of the authors and do not necessarily represent the official views of the NCCAM, NCI, or the National Institutes of Health.

\section{REFERENCES}

1. American Cancer Society. Cancer facts and figures. 2007 [Accessed January 20, 2007]. Available at http://www.cancer.org/downloads/STT/CAFF2007PWSecured.pdf. Updated 2007.

2. Ries, L.; Melbert, D.; Krapcho, M., et al. SEER cancer statistics review, 1975-2005. 2008 [Accessed April 29, 2008]. Available at http://seer.cancer.gov/csr/1975_2005/. Updated 2008.

3. American Cancer Society. Cancer facts and figures for African Americans. 2007-2008. [Accessed January 28, 2008]. Available at http://www.cancer.org/downloads/STT/CAFF2007AAacspdf2007.pdf. Updated 2007.

4. Mellon S, Northouse L. Family survivorship and quality of life following a cancer diagnosis. Research in Nursing \& Health 2001;24(6):446-459. [PubMed: 11746074]

5. Cassileth BR, Lusk EJ, Miller DS, Brown LL, Miller C. Psychosocial correlates of survival in advanced malignant disease? The New England Journal of Medicine 1985;312(24):1551-1555. [PubMed: 4000186] 
6. Kornblith AB, Herr HW, Ofman US, Scher HI, Holland JC. Quality of life of patients with prostate cancer and their spouses. The value of a data base in clinical care. Cancer 1994;73(11):2791-2802. [PubMed: 8194021]

7. Boehmer U, Clark JA. Communication about prostate cancer between men and their wives. The Journal of Family Practice 2001;50(3):226-231. [PubMed: 11252211]

8. Kiley DJ, Lam CS, Pollak R. A study of treatment compliance following kidney transplantation. Transplantation 1993;55:51-56. [PubMed: 8420064]

9. Meyerowitz B, Formenti S, Ell K, Leedham B. Depression among Latina cervical cancer patients. Journal of Social and Clinical Psychology 2000;19:352-371.

10. Ashing-Giwa KT, Kagawa-Singer M, Padilla GV, et al. The impact of cervical cancer and dysplasia: a qualitative, multiethnic study. Psychooncology 2004;13(10):709-728. [PubMed: 15386644]

11. Maliski SL, Heilemann MV, McCorkle R. Mastery of postprostatectomy incontinence and impotence: his work, her work, our work. Oncology Nursing Forum 2001;28(6):985-992. [PubMed: 11475885]

12. Nicklin W. Postdischarge concerns of cardiac patients as presented via a telephone callback system. Heart and Lung 1986;15(3):368-372. [PubMed: 2941394]

13. Butler L, Downe-Wamboldt B, Marsh S, Bell D, Jarvi K. Behind the scenes: partners' perceptions of quality of life post radical prostatectomy. Urologic Nursing 2000;20(4):254-258. [PubMed: 11998088]

14. Taylor KL, Lamdan RM, Siegel JE, Shelby R, Moran-Klimi K, Hrywna M. Psychological adjustment among African American breast cancer patients: one-year follow-up results of a randomized psychoed-ucational group intervention. Health Psychology 2003;22(3):316-323. [PubMed: 12790260]

15. Rassin M, Levy O, Schwartz T, Silner D. Caregivers' role in breaking bad news: patients, doctors, and nurses' points of view. Cancer Nursing 2006;29(4):302-308. [PubMed: 16871098]

16. Courtens AM, Stevens FCJ, Crebolder HFJ, Philipsen H. Longitudinal study on quality of life and social support in cancer patients. Cancer Nursing 1996;19(3):162-169. [PubMed: 8674024]

17. Manuel JC, Burwell SR, Crawford SL, et al. Younger women's perceptions of coping with breast cancer. Cancer Nursing 2007;30(2):85-94. [PubMed: 17413773]

18. Langford CP, Bowsher J, Maloney JP, Lillis PP. Social support: a conceptual analysis. Journal of Advanced Nursing 1997;25(1):95-100. [PubMed: 9004016]

19. Schoenbach VJ, Kaplan BH, Fredman L, Klein-baum DG. Social ties and mortality in Evans County, Georgia. American Journal of Epidemiology 1986;123(4):577-591. [PubMed: 3953538]

20. Letvak S. The importance of social support for rural mental health. Issues in Mental Health Nursing 2002;23(3):249-261. [PubMed: 11942190]

21. Kilbridge K, Fraser G, Krahn M, et al. Assessing prostate cancer outcomes in rural African American men: are common terms understood? Proceedings of the American Society of Clinical Oncology 2001;20:251a.

22. Stewart, D.; Shamdasani, P., editors. Focus Groups: Theory and Practice. Newbury Park, CA: Sage Publications; 1990.

23. Jones RA, Taylor AG, Bourguignon C, et al. Complementary and alternative medicine modality use and beliefs among African American prostate cancer survivors. Oncology Nursing Forum 2007;34 (2):359-364. [PubMed: 17573300]

24. Charles C, Gafni A, Whelan T. Shared decision-making in the medical encounter: what does it mean? (or it takes at least two to tango). Social Science \& Medicine 1997;44(5):681-692. [PubMed: 9032835]

25. Denberg TD, Beaty BL, Kim FJ, Steiner JF. Marriage and ethnicity predict treatment in localized prostate carcinoma. Cancer 2005;103(9):1819-1825. [PubMed: 15795905]

26. Banks I. No man's land: men, illness, and the NHS. BMJ 2001;323(7320):1058-1060. [PubMed: 11691768] 
Table 1

\section{Demographics. $^{*}$}

Age, mean (range), y

Years of education, mean (range)

Annual household income, mean (range), \$

Age at prostate cancer diagnosis, mean (range), y

Marital status, $n(\%)$

Married

Widowed

Single

Occupational status, $n(\%)$

Retired

Employed full-time

Insurance type, ${ }^{\dagger} n$ (\%)

Uninsured

Medicaid

Medicare

Private insurance

Treatment type, $n(\%)$

Prostatectomy

Radiation seeds and Lupron ${ }^{\circledR}$

Radiation seeds

Prostatectomy and Lupron $\mathbb{}$

External beam radiation therapy

Lupron ${ }^{\circledR}$

Family history of prostate cancer, $n(\%)$

Yes

Father only

Uncle only

Brother only

Father and brother

Uncle and brother

No

Survival years after diagnosis (at time of interview), $n(\%), \mathrm{y}$

15

12

10

8

4

3

2

\section{$69.6(51-83)$}

$12.6(6-17)$

$33,848(10,800-70,000)$

$63.3(43-75)$

$9(64.3)$

$3(21.4)$

$2(14.3)$

$10(71.4)$

4 (28.6)

$0(0)$

$6(42.9)$

$7(50)$

$14(100)$

7 (50)

1 (7.1)

3 (21.4)

1 (7.1)

$1(7.1)$

1 (7.1)

8 (57.1)

1 (7.1)

2 (14.3)

3 (21.4)

$1(7.1)$

1 (7.1)

$6(42.9)$

$1(7.1)$

2 (14.3)

1 (7.1)

2 (14.3)

4 (28.6)

1 (7.1)

1 (7.1)

2 (14.3) 
${ }^{*} N=14$.

${ }^{\dagger}$ Some men had multiple types of insurance. 